\title{
Evaluation of $\mathrm{NH}_{4}^{+}$Adsorption Capacity in Water of Coffee Husk- Derived Biochar at Different Pyrolysis Temperatures
}

\author{
Nguyen Van Phuong, ${ }^{1}$ Nguyen Khanh Hoang $\mathbb{D}^{1},{ }^{1}$ Le Van Luan $\mathbb{D}^{2},{ }^{2}$ and L. V. Tan $\mathbb{D}^{3}$ \\ ${ }^{1}$ Institute of Environmental Science, Engineering and Management, Industrial University of Ho Chi Minh City, \\ Ho Chi Minh City 700000, Vietnam \\ ${ }^{2}$ Hue Industrial College, Hue City 49100, Vietnam \\ ${ }^{3}$ Chemical Engineering Faculty, Industrial University of Ho Chi Minh City, Ho Chi Minh City 700000, Vietnam \\ Correspondence should be addressed to Le Van Luan; lvluan@hueic.edu.vn and L. V. Tan; levantan@iuh.edu.vn
}

Received 24 May 2021; Revised 30 June 2021; Accepted 31 July 2021; Published 13 August 2021

Academic Editor: Allen Barker

Copyright (c) 2021 Nguyen Van Phuong et al. This is an open access article distributed under the Creative Commons Attribution License, which permits unrestricted use, distribution, and reproduction in any medium, provided the original work is properly cited.

\begin{abstract}
Ammonium $\left(\mathrm{NH}_{4}^{+}\right)$is a pollutant that can be harmful to the water environment. The purpose of this study is to access $\mathrm{NH}_{4}^{+}$ removal capacity from water by coffee husk-derived biochar. The properties of biochar prepared at different temperatures (300, 450 , and $600^{\circ} \mathrm{C}$ ) were determined including TOC, and $\mathrm{pH}, \mathrm{pH}_{\mathrm{pzc}}$, functional groups of $\mathrm{H}^{+} / \mathrm{OH}^{-}$, cation-exchange capacity (CEC), and the characteristics of groups of organic matter (FT-IR spectrum) were identified and evaluated. The trend of $\mathrm{NH}_{4}^{+}$adsorption equilibrium and kinetics of biochar have been studied. The experimental design of adsorption equilibrium was carried out by exposing biochar to a $\mathrm{NH}_{4}^{+}$solution at different concentrations, ranging from 0 to $50 \mathrm{mg} \mathrm{NH}_{4}^{+} / \mathrm{L}$ for 12 hours. Kinetic surveys were carried out when biochar was exposed to a solution containing $8.3 \mathrm{mg} \mathrm{NH}_{4}^{+} / \mathrm{L}$ for a varying length of time. The results showed that Langmuir and Freundlich models and the pseudo-second-order kinetic model are suitable to explain the $\mathrm{NH}_{4}^{+}$adsorption equilibrium and kinetics on the biochar forms derived from coffee husk. Biochar derived from coffee husk prepared at lower pyrolysis temperature has a higher adsorption capacity. The results suggest that the biochar could be used as an adsorbent ammonium from water.
\end{abstract}

\section{Introduction}

Nitrogen is present in natural water in the forms of organic nitrogen, ammonia, nitrate, and nitrite. In most cases of raw wastewater, nitrogen is normally present in the organic nitrogen and $\mathrm{NH}_{4}^{+}$. Ammonia also can be naturally generated in the environment [1]. The presence of $\mathrm{NH}_{4}^{+}$at high concentrations can contribute to eutrophication and the subsequent devastation of aquatic life. The residual amount of ammonium in water causes ecological issues in relation to eutrophication, acidification of freshwater ecosystems, and in anoxic conditions, poisoning benthic organisms and fish [2]. According to Eddy, the ammoniac tolerance in freshwater fishes ranges from 0.07 to $2.00 \mathrm{mg} / \mathrm{L} \mathrm{[3].} \mathrm{At} \mathrm{a}$ dose of more than $33.7 \mathrm{mg}$ of ammonium ion per $\mathrm{kg}$ of body weight per day, it influences the metabolism by shifting the acid-base equilibrium, disturbing the glucose tolerance, and reducing the tissue sensitivity to insulin [4].

Therefore, removal of nitrous ammonium in polluted water is necessary. Many methods of removing $\mathrm{NH}_{4}^{+}$from water have been used, including ion adsorption and exchange, which is more effective than the others, yet of high cost [5]. Looking for new renewable materials that can be used in ion adsorption and exchange is a crucial research topic. Biochar prepared from agricultural waste is a useful material due to its efficiency, low cost, environment friendliness, and availability in large quantity [6]. Adsorption of inorganic pollutants by biochar is the result of (i) ion exchange, (ii) electrostatic attraction, or (iii) surface precipitation [7]. In the case of ammonium, mostly electrostatic exchange and interaction is used; moreover, Khalil et al. stated that biochar's surface chemistry is more important 
than the material's surface area $[5,8]$. However, surface chemistry properties are controlled by the pyrolysis condition, especially temperatures, heating, and heat-keeping time [9]. Ammonium adsorption capability by biochar which was prepared with varying pyrolysis temperatures among research is not always alike [10]. There have been studies which use biochar derived from corn plants, red oak (Quercus rubra), maple trees, and wheat plants to adsorption of ammonium [10].

Vietnam is the No. 1 producer of robusta coffee in the world, accounting for more than $40 \%$ of the global output in the 2019-2020 marketing year [11]. Coffee husks are the major solid residues from the processing of coffee, for which there are no current profitable uses, and their adequate disposal constitutes a major environmental problem. Dak Lak is a leading coffee-producing province in Vietnam with over 200,000 ha of coffee fields, and its annual coffee production reaches 450,000 tons. Together with about 250,000 tons of coffee husk to be discharged, it is a valuable material, yet has not been used efficiently [12]. Thus, innovative techniques and products for the profitable and adequate use of this type of residue are being sought. We have been also interested in the adsorption of metal ion, textile dyes, etc. on different materials [13-15]. In this work, we are reporting the assessment of $\mathrm{NH}_{4}^{+}$in the water adsorption capability of biochar derived from coffee husk at different pyrolysis temperatures.

\section{Materials and Methodology}

2.1. Sampling Method. The coffee husk was collected in January 2019 from a household at Hamlet 8, 9A village, Pong Drang Commune, Krong Buk Town, Dak Lak Province. The location of the sampling site is $12^{\circ} 34^{\prime} 43.8^{\prime \prime} \mathrm{N} 108^{\circ} 01^{\prime} 39.3^{\prime \prime} \mathrm{E}$. The composite samples were obtained from the coffee peeling process. Coffee husk was dried at $60^{\circ} \mathrm{C}$ for 24 hours and stored in polyethylene bags [16].

2.2. Chemicals. All chemicals used in the study were of analytical grade. Storage solution concentration was $\mathrm{NH}_{4}^{+}$ $1000 \mathrm{mg} / \mathrm{L}$. Sample water was distilled water and was purified by the model EASYpure II RF from Thermo Scientific, USA. Instruments must be cleaned by being filled with nitric acid for 24 hours and then cleaned by demineralized water [17].

2.3. Experimental Design. The biochar modulation refers to the research of Yoo et al., where processed coffee husk was furnaced in a Naberthem P330 furnace at 300, 450, and $600^{\circ} \mathrm{C}[18]$. The heating rate was set to $10^{\circ} \mathrm{C} \cdot \mathrm{min}^{-1}$. Once the desired temperature was reached, the temperature was kept constant for 2 hours and the samples were let to cool in the oven overnight. The biochar was then pressed through a plastic sieve (hole diameter of $1 \mathrm{~mm}$ ) to make it homogeneous and was stored separately in polyethylene (PE) containers in dark at $4^{\circ} \mathrm{C}$ [18]. Biochar samples were analyzed and used to conduct equilibrium and kinetics experiments. Parameters including recovery efficiency and surface functional groups were determined. Analyses were conducted on these biochar samples to determine characteristics of surface functional groups such as $\mathrm{pH}$ and $\mathrm{pH}_{\mathrm{pzc}}$ [19], total organic carbon (TOC) [20], functional group $\mathrm{H}^{+}$/ $\mathrm{OH}^{-}[21]$, and cation-exchange capacity (CEC) based on the Walkley Black method. Changes in biochar's functional groups were analyzed by reflectance spectroscopy FT-IR4700 type A with $350-4000 \mathrm{~cm}^{-1}$ resolution.

Equilibrium experiment of $\mathrm{NH}_{4}^{+}$ion adsorption on biochar refers to the work of Khalil et al. and Xue et al. $[5,22]$. The experiment was performed in $50 \mathrm{~mL}$ polypropylene tubes, and $0.3 \mathrm{~g}$ biochar was mixed with $30 \mathrm{~mL}$ of $\mathrm{NH}_{4}^{+}$solution. The concentration of the diluted $\mathrm{NH}_{4}^{+}$solution varied between 0 and $50 \mathrm{mg} \cdot \mathrm{L}^{-1}$. Two drops of chloroform were added to prevent microbial activities. The initial $\mathrm{pH}$ of the solutions was adjusted to $5.0-5.5$ by adding either dilute $\mathrm{HCl}$ or $\mathrm{NaOH}$ solutions ( $\mathrm{pH}$ value is close to that of natural surface water sources). The mixtures were then shaken by using a GFL3015 orbital shaker with frequency 150 round-per-minute (rpm) in 12 hours (which is the time for the $\mathrm{NH}_{4}^{+}$adsorption to reach the equilibrium, determined by preliminary experiments.). After that, the solutions were not adjusted during this experiment. The solid settlement was separated from the mixture by using a DLAB DM0636 centrifuge at $4000 \mathrm{rpm}$ for $15 \mathrm{~min}$. Then, the remaining solution was filtered through a $0.22 \mu \mathrm{m}$ filter. $\mathrm{NH}_{4}^{+}$was determined according to ISO 7150-1: 1984 (E). Langmuir and Freundlich adsorption isotherms models were used in evaluating the suitability of experimental data.

Ion adsorption kinetics survey was conducted by mixing $0.3 \mathrm{~g}$ biochar and $30 \mathrm{~mL}$ of $8.3 \mathrm{mgNH}_{4}^{+} / \mathrm{L}$ solution. The mixture was then shaken at $150 \mathrm{rpm}$. All the samples went through shaking intervals $5 ; 10 ; 15 ; 20 ; 30 ; 40 ; 60 ; 90$; and 120 minutes and then were filtered to conduct $\mathrm{NH}_{4}^{+}$analysis. Pseudo-first- and second-order kinetic models were used to consider experiment data and to estimate kinetic parameters.

\subsection{Data Processing}

\subsubsection{Calculation Methods}

(i) Productivity efficiency of biochar is

$$
\% \text { production efficiency }=\frac{m_{b}}{m_{0}} * 100,
$$

where $m_{0}(\mathrm{~g})$ is the initial coffee mass before being furnaced; $m_{\mathrm{b}}(\mathrm{g})$ is the biochar mass after being furnaced.

(ii) $\mathrm{pH}_{\mathrm{pzc}}$ of biochar is

$$
\Delta \mathrm{pH}=\left(\mathrm{pH}_{f}-\mathrm{pH}_{i}\right)
$$

where $\mathrm{pH}_{i}$ : initial $\mathrm{pH}$ value; $\mathrm{pH}_{f}: \mathrm{pH}$ value after biochar is added to the $0.01 \mathrm{M} \mathrm{KCl}$ solution (they were shaken for $2 \mathrm{~h}$ and allowed to settle for $48 \mathrm{~h}$ ). Plotting $\Delta \mathrm{pH}$ according to the initial $\mathrm{pH}, \mathrm{pH}_{\mathrm{pzc}}$ is where the $\mathrm{pH}$ curve overcomes $\Delta \mathrm{pH}=0$ [19]. 
(iii) Adsorption equilibrium:

Adsorption capacity, mg/g:

$$
q i=\frac{\left(C_{0}-C_{i}\right) \times V}{m}
$$

where $C_{0}(\mathrm{mg} / \mathrm{L})$ is the initial $\mathrm{NH}_{4}^{+}$ion concentration, $C_{i}(\mathrm{mg} / \mathrm{L})$ is the adsorbed $\mathrm{NH}_{4}^{+}$concentration at equilibrium, $V(L)$ is the $\mathrm{NH}_{4}^{+}$solution volume, $m(\mathrm{~g})$ is the adsorbent mass (biochar), And $q_{i}(\mathrm{mg} / \mathrm{g})$ is the $\mathrm{NH}_{4}^{+}$adsorption capacity at equilibrium.

Langmuir isothermal equation:

$$
\frac{1}{q i}=\frac{1}{K_{L} q_{0}} \frac{1}{C_{i}}+\frac{1}{q_{0}},
$$

where $q_{0}\left(\mathrm{mg} \cdot \mathrm{g}^{-1}\right): \mathrm{NH}_{4}^{+}$maximum adsorption capacity at equilibrium; $K_{L}\left(\mathrm{~L} \cdot \mathrm{mg}^{-1}\right)$ : Langmuir adsorption constant.

The abovementioned equation has the form of $y=a x+b$, and therefore, it could be solved by curve fitting $y=1 / q_{i}$ and $x=1 / C_{i}$ to yield $R^{2}, q_{0}$. Freundlich isothermal equation:

$$
q=\frac{y}{m}=K_{F} C^{\left(1 / n_{F}\right)}
$$

or

$$
\log q_{i}=\frac{1}{n_{F}} \log C_{i}+\log K_{F}
$$

where $n_{F}$ is the Freundlich isothermal constant for $\mathrm{NH}_{4}^{+}$adsorption intensity; $K_{F}$ is the Freundlich isothermal adsorption constant for adsorption capacity.

This equation also has the form of $y=a x+b$, and as all the parameters are known, the plot of $\log q_{i}$ against $\log C_{i}$ can be drawn.

(iv) Adsorption kinetics:

Pseudo-first- and second-order (PFO and PSO) reaction models were usually used to study the adsorption mechanism, in order to assess adsorption kinetics parameters.

Pseudo-first-order kinetics equation:

$$
\operatorname{Ln}\left(q_{e}-q_{t}\right)=-k_{1} t+\operatorname{Ln} q_{e}
$$

$\operatorname{Ln}\left(q_{e}-q_{t}\right)$ is plotted according to $t$.

Pseudo-second-order kinetics equation:

$$
\frac{1}{q_{t}}=\frac{1}{t} \frac{1}{k_{2} q_{e}^{2}}+\frac{1}{q_{e}} .
$$

The abovementioned equation has the form of $y=a x+b$, and therefore, it could be solved by curve fitting $y=1 / q_{t}$ and $x=1 / t$ to yield $R^{2}, q_{e}$ is the $\mathrm{NH}_{4}^{+}$adsorption capacity at equilibrium (mg/g), $q_{t}$ is the $\mathrm{NH}_{4}^{+}$adsorption capacity at time $t, k_{1}(1 /$ minute) and $k_{2}$ (g/mg .minute) are the pseudo-first- and secondorder kinetics constants, and $t$ (minute) is the adsorption time.
2.4.2. Data Processing. Control and replicate samples $(n=3)$ were employed in order to minimize error sources. The analysis evaluated the accuracy and precision of the parameters calculated using the methods described in the previous section. SPSS 20.0 was used to determine variance's homogeneity, and root mean square of the results was then calculated with $p$ value $<0.05$ using Tukey's test post hoc if Sig $>0.05$ or Tamhane if Sig $<0.05$.

\section{Results and Discussion}

3.1. Influences of Chemical Synthesis Temperatures on Productivity Efficiency and Surface Chemistry of Biochar. The study showed that chemical synthesis temperatures affect productivity efficiency and surface chemistry of coffee husk biochar; Table 1 illustrates that, with increasing temperatures of 300,450 , and $600^{\circ} \mathrm{C}$, recovery efficiency $(\% \mathrm{H})$ decreased at $51.4,34.9$, and $30.7 \%$, respectively. This was due to the reduction of volatile substances in biochar [8]. The results were consistent with those from the work of Yavari et al. which reported a decrease in recovery efficiency when biochar pyrolysis temperature rises from 300 to $700^{\circ} \mathrm{C}$ $[23,24]$. Biochar acquired at $300^{\circ} \mathrm{C}$ was statistically significantly different to the ones at 450 and $600^{\circ} \mathrm{C}$, while biochar produced at 450 and $600^{\circ} \mathrm{C}$ was not statistically significantly different.

Total Organic Carbon (\%TOC) in Table 1 shows that, with increasing temperatures of 300,450 , and $600^{\circ} \mathrm{C}$, \% TOC decreased at $25.5,10.4$, and $1.5 \%$, respectively, which was consistent with the findings by the previous studies $[8,23]$. This was related to the production of organic acids and phenolic compounds due to thermal decomposition of cellulose and hemicellulose compounds in the pyrolysis temperature range of the study [23] and the removal of water, hydrocarbons, $\mathrm{H}_{2}, \mathrm{CO}$, and $\mathrm{CO}_{2}$ during the carbonization process [8]. \%TOC of biochar samples had statistically significant differences. $\mathrm{pH}$ values at 7.59, 9.16, and 9.69, respectively, to the biochar pyrolysis temperatures 300,450 , and $600^{\circ} \mathrm{C}$, the $\mathrm{pH}$ values were also statistically significantly different (Table 1). This is due to the partial transformation of organic matters into ashes, which releases alkali salts and increases the $\mathrm{pH}$ level of biochar [25].

Similar to $\mathrm{pH}, \mathrm{pH}_{\mathrm{pzc}}$ values at 7.2, 8.2, and 9.5, respectively, were also statistically significantly different. With the increase in biochar pyrolysis temperatures, the number of acid functional groups $\left(\mathrm{H}^{+}\right)$decreased and the values of $\mathrm{H}^{+}$functional groups were statistically significantly different. The number of base functional groups $\left(\mathrm{OH}^{-}\right)$increased at $11.17,11.24$, and $12.50 \mathrm{mmolOH}^{-} \cdot \mathrm{g}^{-1}$, respectively, to the increasing biochar pyrolysis temperatures, and the value at $600^{\circ} \mathrm{C}$ was statistically significantly different from the ones at 300 and $450^{\circ} \mathrm{C}$, whereas the values at 300 and $450^{\circ} \mathrm{C}$ were not. This observation matched the conclusion reached by Mukherjee et al. and Yang et al. el. in regard to biochar originating from plant $[26,27]$. CEC values were 309, 290, and $266 \mathrm{mmol} . \mathrm{kg}^{-1}$, respectively. Decreasing CEC values were statistically significantly different with increasing biochar pyrolysis temperatures, and a similar conclusion was stated by Fidel et al. [10]. 
TABle 1: Productivity efficiency and surface physical chemistry properties of biochar.

\begin{tabular}{|c|c|c|c|c|c|c|c|}
\hline$t^{\circ} \mathrm{C}$ & $\% H$ & $\mathrm{pH}$ & $\mathrm{pH}_{\mathrm{pzc}}$ & $\mathrm{mmolH}^{+} \cdot \mathrm{g}^{-1}$ & $\mathrm{mmolOH}{ }^{-} \cdot \mathrm{g}^{-1}$ & \% TOC & $\mathrm{CEC}, \mathrm{mmol} \cdot \mathrm{kg}^{-1}$ \\
\hline 300 & $51,4^{b}$ & $7,59^{\mathrm{a}}$ & $7,2^{a}$ & $1,73^{c}$ & $11,17^{a}$ & $25,5^{c}$ & $309^{c}$ \\
\hline SD & 0,8 & 0,16 & 0,1 & 0,11 & 0,15 & 1,0 & 11 \\
\hline 450 & $34,9^{a}$ & $9,16^{\mathrm{b}}$ & $8,2^{b}$ & $0,50^{b}$ & $11,24^{a}$ & $10,4^{b}$ & $290^{b}$ \\
\hline SD & 0,6 & 0,02 & 0,0 & 0,10 & 0,04 & 0,3 & 3 \\
\hline 600 & $30,7^{a}$ & $9,69^{c}$ & $9,5^{c}$ & $0,17^{a}$ & $12,50^{b}$ & $1,5^{a}$ & $266^{a}$ \\
\hline SD & 4,0 & 0,02 & 0,3 & 0,06 & 0,04 & 0,3 & 1 \\
\hline
\end{tabular}

$a, b, c$ in a column illustrate statistically significant differences $(p<0.05)$. SD: standard deviation.

Analyzing the relationship between the parameters, Table 2 showed that the biochar pyrolysis temperatures were correlating and proportional to $\mathrm{pH}, \mathrm{pH}_{\mathrm{pzc}}$, and $\mathrm{mmolOH}^{-}$ and reversely proportional to $\% \mathrm{H}, \mathrm{mmolH}^{+}, \% \mathrm{TOC}$, and CEC.

Analysis results by FT-IR reflectance spectroscopy, Figure 1, showed that the featured through series at $3251 \mathrm{~cm}^{-1}$ and $1575 \mathrm{~cm}^{-1}$ of biochar $300^{\circ} \mathrm{C}$ clearly indicated the presence of ${ }^{-} \mathrm{OH}$ and $\mathrm{COO}^{-}$groups, the results showed that the carboxylase group decreased with increasing biochar pyrolysis temperatures, and similar conclusions were stated by Fidel et al. [10] and Thuy and Do [28]. This suggested a decrease in the polar organic functional groups with an increase in pyrolysis temperature [8]. Series at $1076 \mathrm{~cm}^{-1}$ were assumed to be due to the decrease of $\mathrm{C}-\mathrm{O}$ in connection with the increasing pyrolysis temperatures [29]. An aromatic hydrocarbon peak $\left(789 \mathrm{~cm}^{-1}\right)$ was observed at 450 and $600^{\circ} \mathrm{C}$, which was in accordance with the study by Lugovoy et al. showing that lignin decomposition occurs at $280-500^{\circ} \mathrm{C}[30]$. The interchangeable results were concluded by Park et al. who also studied biochar derived from coffee husk produced at $300,400,500$, and $600^{\circ} \mathrm{C}$ [31].

3.2. Adsorption Equilibrium $\mathrm{NH}_{4}^{+}$in Water of Biochar. Results of the $\mathrm{NH}_{4}^{+}$adsorption equilibrium experiments of biochar derived from coffee husk produced at varying temperatures showed that adsorption capacity increased with increasing the initial $\mathrm{NH}_{4}^{+}$concentration in all 3 biochar forms and they all reached saturation in the experimental condition (Figure 2). Increasing the initial $\mathrm{NH}_{4}^{+}$concentration resulted in competition among cation in the solution, which promoted adsorption chance and capacity [5], specifically when raising $C_{0}$ from 0 to $50 \mathrm{mgNH}_{4}^{+} \cdot \mathrm{L}^{-1}$, the maximum capacity at equilibrium (saturated) was 1.8, 1.4, and $1.1 \mathrm{mg} \cdot \mathrm{g}^{-1}$, respectively, to biochar produced at 300,450 , and $600^{\circ} \mathrm{C}$ (Figure 2). One-way ANOVA on data of the adsorption showed that ammonium adsorption values varied and there were statistically significant differences in initial ammonium concentration ranging from 0 to $25 \mathrm{mg} \cdot \mathrm{L}^{-1}$. Ammonium concentrations from 25 to $50 \mathrm{mg} \cdot \mathrm{L}^{-1}$ were statistically insignificantly different. This indicated the adsorption process which reached saturation. The same explanation is also used for the case of biochar at 450 and $600^{\circ} \mathrm{C}$ (Figure 2).

The data (Figure 2, Table 3) showed that Langmuir and Freundlich models were suitable to describe the $\mathrm{NH}_{4}^{+}$ adsorption, with $R^{2}$ greater than 0.95 in all the 3 biochars, and maximum adsorption values are $1.5,1.2$ and $0.9 \mathrm{mg} \mathrm{g}^{-1}$, respectively, to 300,450 , and $600^{\circ} \mathrm{C}$ biochar, which fitted the experiment values. Other studies also reported that the ammonium adsorption onto some biochars followed both the Langmuir and Freundlich models $[32,33] . R^{2}$ values of the Langmuir model were $0.97,0.95$, and 0.96 , respectively, which were slightly less than those of the Freundlich model, 0.97, 0.99, and 0.97, respectively. Therefore, the Freundlich adsorption isotherm appeared to be more favorable in describing the adsorption of ammonium onto the coffee husk-derived biochar surface than the Langmuir model. The Freundlich model indicated the heterogenous nature of the biochar surfaces. In light of the heterogeneity nature of the biochar surface, ammonium adsorption would occur at multiple layers onto sites where nonuniform energy distribution could occur. Similar observations were also found in the study of Fan et al. [8, 34]. The adsorption capacity decreased with increasing biochar pyrolysis temperatures $[8,28]$. The decrease in adsorption capacity may be due to reduction of organic groups such as $-\mathrm{COOH}$ and $-\mathrm{OH}$ on the surface of biochar samples (Figure 1). The study used biochar produced from maple trees at $500^{\circ} \mathrm{C}$ and generated a Langmuir maximum adsorption capacity of $0.99 \mathrm{mg} \mathrm{NH} \mathrm{m}_{4}^{+} \cdot \mathrm{g}^{-1}$ at $\mathrm{pH} 5.9$ [35]. In the study of Thuy and Do, ammonium adsorption capacity on biochar derived from coffee husk was relatively high after 6 hours with maximum $2.8 \mathrm{mg} \cdot \mathrm{N} \cdot \mathrm{g}^{-1}$ biochar [28]. The higher adsorption capacity can be attributed to the biochar being prepared at $350^{\circ} \mathrm{C}$, but the heat retention time is much shorter, only 1 hour.

Langmuir adsorption constantly follows a downward trend with increasing temperatures, and the same conclusion is found in the work of Fidel et al., on certain biochar [10]. In terms of the Freundlich model, $n_{F}$ greater than 1 indicates exposure to the adsorption (for $n_{F}$ represents the surface exchange intensity or surface heterogeneity) [5].

According to the work in [6], better adsorption of the $\mathrm{NH}_{4}^{+}$of biochar with lower pyrolysis temperatures was assumed to be related to cation-exchange capacity (CEC) with greater quantity carboxylase groups on the biochar's surface, where adsorbing positions locate, and this finding fits the results of this study. The results showed that $\mathrm{NH}_{4}^{+}$adsorption on coffee husk biochar occurred mainly by cation $\mathrm{H}^{+}$on functional groups containing surface oxygen; therefore, high adsorption capacity means low pyrolysis temperature. Additionally, the adsorption capacity shrinks with increasing temperatures because of the increasing competition among ions in organic minerals $(\mathrm{K}, \mathrm{Fe}, \mathrm{Zn}, \mathrm{Ca}$, and $\mathrm{Mg}$ ) in biochar 
TABLE 2: Correlations between physical chemistry properties of biochar.

\begin{tabular}{|c|c|c|c|c|c|c|c|c|}
\hline & $t^{\circ} \mathrm{C}$ & $\% H$ & $\mathrm{pH}$ & $\mathrm{pH}_{\mathrm{pzc}}$ & $\mathrm{mmolH}^{+} \cdot \mathrm{g}^{-1}$ & $\mathrm{mmolOH}{ }^{-} \cdot \mathrm{g}^{-1}$ & $\%$ TOC & CEC, mmol.kg ${ }^{-1}$ \\
\hline$t^{\circ} \mathrm{C}$ & 1 & $-0.924^{* *}$ & $0.958^{* *}$ & $0.984^{* *}$ & $-0.943^{* *}$ & $0.883^{* *}$ & $-0.988^{* *}$ & $-0.954^{* *}$ \\
\hline$\% \mathrm{H}$ & $-0.924^{* *}$ & 1 & $-0.970^{* *}$ & $-0.854^{* *}$ & $0.962 * *$ & $-0.673 *$ & $0.958^{* *}$ & $0.875^{* *}$ \\
\hline$p H$ & $0.958^{* *}$ & $-0.970 * *$ & 1 & $0.919 * *$ & $-0.990 * *$ & $0.730^{*}$ & $-0.985^{* *}$ & $-0.904^{* *}$ \\
\hline$p H_{p z c}$ & $0.984^{* *}$ & $-0.854^{* *}$ & $0.919^{* *}$ & 1 & $-0.905^{* *}$ & $0.907^{* *}$ & $-0.960 * *$ & $-0.922 * *$ \\
\hline $\mathrm{mmolH}^{+} \cdot \mathrm{g}^{-1}$ & $-0.943^{* *}$ & $0.962 * *$ & $-0.990^{* *}$ & $-0.905^{* *}$ & 1 & $-0.692^{*}$ & $0.976^{* *}$ & $0.863^{* *}$ \\
\hline $\mathrm{mmolOH}^{-} \cdot \mathrm{g}^{-1}$ & $0.883^{* *}$ & $-0.673^{*}$ & $0.730^{*}$ & $0.907^{* *}$ & $-0.692 *$ & 1 & $-0.800^{* *}$ & $-0.876^{* *}$ \\
\hline$\%$ TOC & $-0.988^{* *}$ & $0.958^{* *}$ & $-0.985^{* *}$ & $-0.960^{* *}$ & $0.976^{* *}$ & $-0.800^{* *}$ & 1 & $0.940^{* *}$ \\
\hline CEC, $\mathrm{mmol} \cdot \mathrm{kg}^{-1}$ & $-0.954^{* *}$ & $0.875^{* *}$ & $-0.904^{* *}$ & $-0.922^{* *}$ & $0.863^{* *}$ & $-0.876^{* *}$ & $0.940 * *$ & 1 \\
\hline
\end{tabular}

*** The correlation is significant at $0.01 ;{ }^{*}$ the correlation is significant at 0.05 .

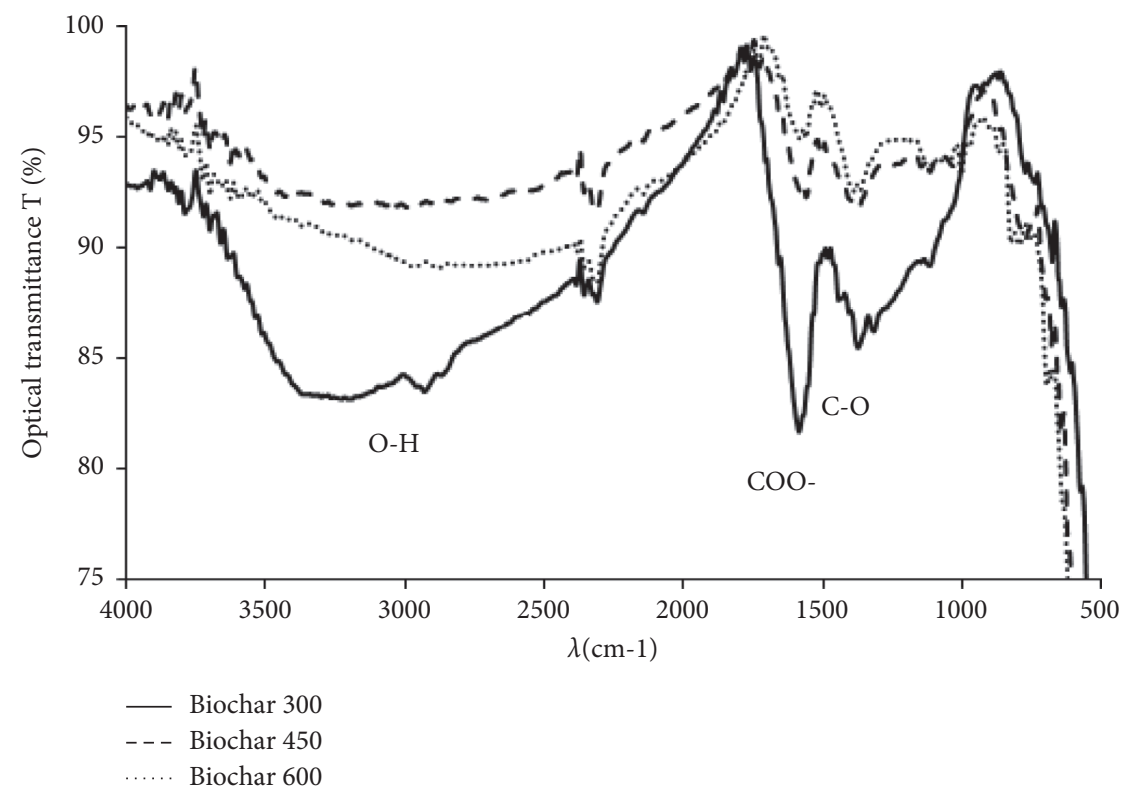

Figure 1: Biochar's FT-IR spectra at 300,450 , and $600^{\circ} \mathrm{C}$.

with increasing temperatures [36]. Similar results were also found in the study of Fidel et al., which suggested that, with increasing pyrolysis temperature, the $\mathrm{NH}_{4}^{+}$adsorption capacity of biochar decreased [10]. This finding was also mentioned by Gao et al. who studied the ammonium adsorption capability of biochar from peanut shells, corn cobs, and cotton tree trunks at 300,450 , and $600^{\circ} \mathrm{C}$ and kept in 2 hours [33]. The study's result matched with the work of of Begum et al. of pyrolyzed woodchips at $700^{\circ} \mathrm{C}$ whose result was $0.96 \mathrm{mg} \cdot \mathrm{g}^{-1}$ [32].

To investigate the main factors influencing biochar's ability to adsorb $\mathrm{NH}_{4}^{+}-\mathrm{N}$, correlations between $q_{0}$, some properties of biochar, biochar pyrolysis temperature, and CEC of biochars were analyzed, Table 4. Maximum $\mathrm{NH}_{4}^{+}$ adsorption capacity $q_{0}$ was positively correlated with the total organic content in the biochar ( $r$ 0.986) (Table 4). This indicated that the removal of the organic functional groups with increasing pyrolysis temperature induced the decreasing $\mathrm{NH}_{4}^{+}$adsorption capacity of biochar. CEC seemed to be the dominating factor influencing the $\mathrm{NH}_{4}^{+}$adsorption capacity of biochar. The $q_{0}$ values were positively correlated with CEC ( $r$ 0.954). That is to say, the biochar with higher CEC values had larger $\mathrm{NH}_{4}^{+}$adsorption capacity. The $q_{0}$ values were negatively correlated with biochar pyrolysis temperature, $t^{\circ} \mathrm{C}(r-1,000)$ so that $\mathrm{NH}_{4}^{+}$adsorption capacity of the biochar also decreased with increasing pyrolysis temperatures.

3.3. The $\mathrm{NH}_{4}^{+}$Adsorption Kinetics of Biochar. The $\mathrm{NH}_{4}^{+}$adsorption in the water process of biochar with varying pyrolysis temperatures and exposure time periods, Figure 3, showed that adsorption kinetics occurs in 3 kinetic phases: the fast phase, slow phase, and ultraslow phase. The adsorption was dramatic within the first 15 minutes in 300, 450 , and $600^{\circ} \mathrm{C}$ biochars. The adsorption capacity reached $82.0,83.8$, and $84.2 \%$, respectively, to the 3 biochars and then slowed down and reached the equilibrium after 45 minutes. The speed of the reaction can be explained in the fast phase, where some anionic groups with negative charges were located on the surface of the adsorbent such as $-\mathrm{COO}^{-}$. These groups rapidly interacted with ammonium ions. Then, the $\mathrm{NH}_{4}^{+}$went into a slow process, which represented the adsorption in the internal part of the biochar [5]. So, the $\mathrm{NH}_{4}^{+}$adsorption on biochar goes through (hoặc chia thì quá khứ) two reaction processes. 

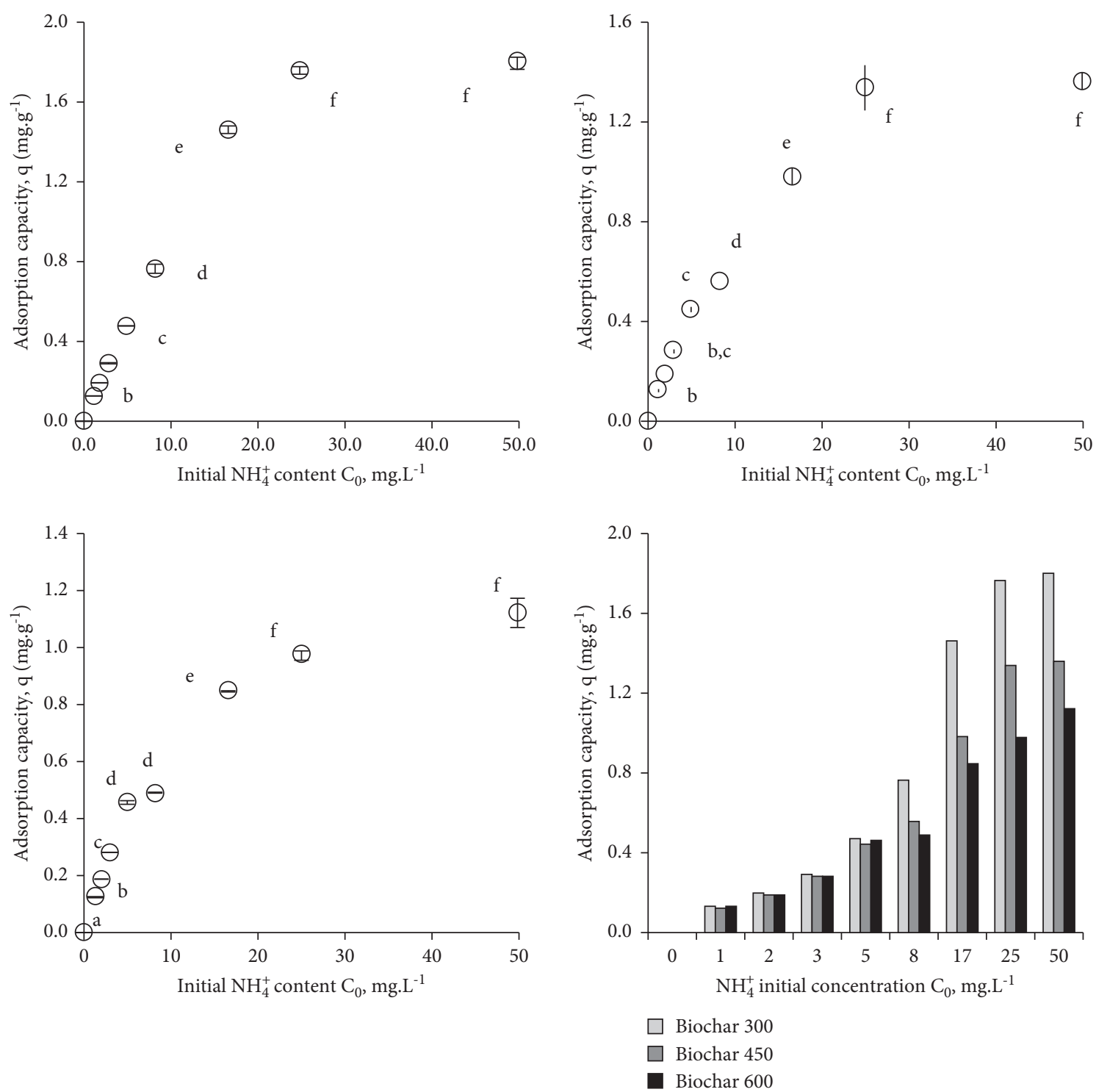

FIGURE 2: Adsorption capacity $\mathrm{NH}_{4}^{+}\left(\mathrm{mg}^{-\mathrm{g}^{-1}}\right)$ vs .Co $\left(\mathrm{mg} \cdot \mathrm{L}^{-1}\right)$ at different pyrolytic temperatures. Different letters represent statistically significant differences. (a) Biochar at $300^{\circ} \mathrm{C}$, (b) biochar at $450^{\circ} \mathrm{C}$, (c) biochar at $600^{\circ} \mathrm{C}$, and (d) adsorption efficiency of 3 forms of biochar.

TABLE 3: Parameters of $\mathrm{NH}_{4}^{+}$adsorption isothermal models.

\begin{tabular}{|c|c|c|c|c|c|c|c|c|}
\hline \multicolumn{2}{|c|}{ Form } & \multicolumn{4}{|c|}{ Parameters of the Langmuir model } & \multicolumn{3}{|c|}{$\begin{array}{c}\text { Parameters of the Freundlich } \\
\text { model }\end{array}$} \\
\hline & & $\mathbf{K}_{\mathrm{L}}$ & $\mathbf{R}^{2}$ & $\mathbf{q}_{0}$ & $\mathbf{q}_{\text {Exp }}$ & $K_{F}$ & $\mathbf{n}_{\mathrm{F}}$ & $\mathbf{R}^{2}$ \\
\hline \multirow{2}{*}{ Biochar $300^{\circ} \mathrm{C}$} & Value & 2.5 & 0.97 & 1.5 & 1.80 & 0.9 & 1.5 & 0.97 \\
\hline & SD & 0.1 & & 0.1 & 0.03 & 0.2 & 0.9 & \\
\hline \multirow{2}{*}{ Biochar $450^{\circ} \mathrm{C}$} & Value & 1.1 & 0.95 & 1.23 & 1.36 & 1.0 & 1.0 & 0.99 \\
\hline & SD & 0.1 & & 0.04 & 0.03 & 0.3 & 0.9 & \\
\hline \multirow{2}{*}{ Biochar $600^{\circ} \mathrm{C}$} & Value & 2.3 & 0.96 & 0.88 & 1.12 & 0.8 & 1.7 & 0.97 \\
\hline & $\mathrm{SD}$ & 0.5 & & 0.06 & 0.05 & 0.4 & 1.3 & \\
\hline
\end{tabular}

According in ANOVA analysis, differences in average experiment results showed, that after 30 minutes, the increasing $\mathrm{NH}_{4}^{+}$adsorption capacity was not statistically significant $(p<0.05)$ in all the 3 biochars (Figure 3$)$. This showed that the process reached a saturated adsorption state.
Simulations from the first-order and second-order models described the experimental data fairly well with $R^{2}$ values larger than 0.89 . However, only the pseudo-secondorder kinetic model with $q_{e}$ derived from the model and the experiment was satisfactory; specifically, the modelled 
TABLE 4: Correlations between some properties of biochar and maximum $\mathrm{NH}_{4}^{+}$adsorption capacity.

\begin{tabular}{lcccc}
\hline & $t^{\circ} \mathrm{C}$ & $\% \mathrm{TOC}$ & $\mathrm{CEC}, \mathrm{mmol} \cdot \mathrm{kg}^{-1}$ & $q_{0} \mathrm{NH}_{4}^{+}, \mathrm{mg}^{-1}$ \\
\hline$t^{\circ} \mathrm{C}$ & 1 & $-0.988^{* *}$ & $-0.954^{* *}$ & $-1.000^{* *}$ \\
$\%$ TOC & $-0.988^{* *}$ & 1 & $0.940^{* *}$ & $0.986^{* *}$ \\
$\mathrm{CEC}, \mathrm{mmol.kg}{ }^{-1}$ & $-0.954^{* *}$ & $0.940^{* *}$ & 1 & $0.954^{* *}$ \\
$q_{0} \mathrm{NH}_{4}^{+}, \mathrm{mg}^{-1}$ & $-1.000^{* *}$ & $0.986^{* *}$ & $0.954^{* *}$ & 1 \\
\hline
\end{tabular}

${ }^{* *}$ Correlation is significant at the 0.01 level $(2$ tailed). * Correlation is significant at the 0.05 level ( 2 tailed).
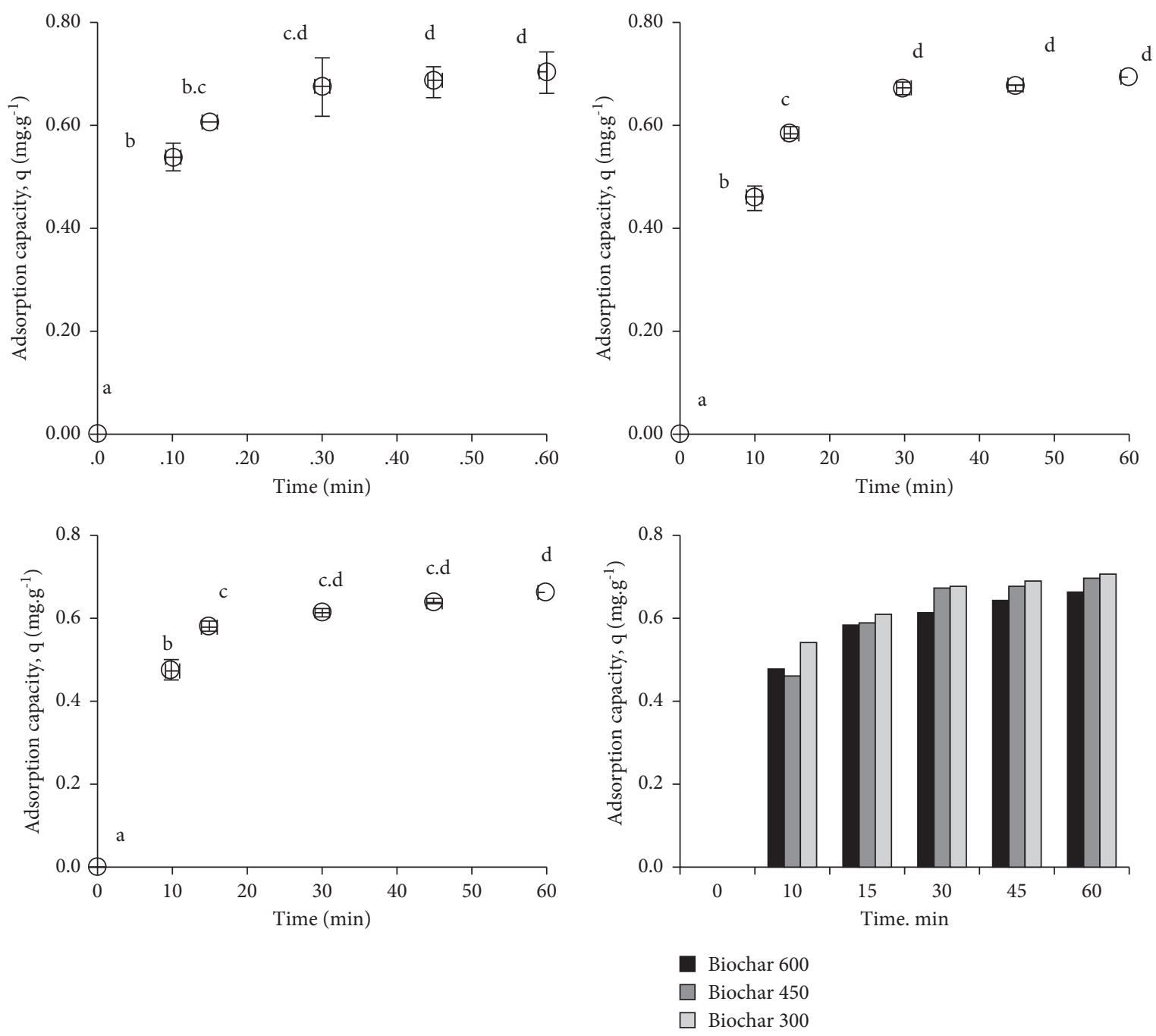

FIGURE 3: Illustration of $\mathrm{NH}_{4}^{+}$adsorption capacity ( $\mathrm{mg} / \mathrm{g}$ ) by time $t$ (min) of the biochar; ${ }^{a, b, c, d}$ indicate statistically significant differences. (a) Biochar at $300^{\circ} \mathrm{C}$, (b) biochar at $450^{\circ} \mathrm{C}$, (c) biochar at $600^{\circ} \mathrm{C}$, and (d) adsorption efficiency of 3 forms of biochar.

$q_{e}$ of the 300,450 , and $600^{\circ} \mathrm{C}$ biochar was $0.77,0.78$, and $0.75 \mathrm{mg} \cdot \mathrm{g}^{-1}$, respectively, while the experimented $q_{e}$ was $0.74,0.70$, and $0.69 \mathrm{mg} \cdot \mathrm{g}^{-1}$ (Table 5). Therefore, using the pseudo-second-order kinetic model to explain the $\mathrm{NH}_{4}^{+}$ adsorption kinetic of biochar derived from coffee husks was suitable. The same was also confirmed from the finding of Khalil et al. [5]. This also means that the kinetics was controlled by valency-related adsorptions by sharing or ion-exchanging between adsorbents and adsorbates [37]. The $\mathrm{k}_{2}$ parameter did not behave in a particular trend when increasing the pyrolysis temperature from 300 to $600^{\circ} \mathrm{C}$. 
TABLE 5: $\mathrm{NH}_{4}^{+}$adsorption kinetics parameters of biochar.

\begin{tabular}{lcccr}
\hline Models & Pyrolytic temperature & $q_{e}\left(\mathrm{mg} \cdot \mathrm{g}^{-1}\right)$ & Kinetic constant & $q_{e}$ of experiment, mg.g \\
\hline \multirow{3}{*}{ Pseudo-first-order } & Biochar $300^{\circ} \mathrm{C}$ & -0.19 & $k_{1}\left(1 . \mathrm{min}^{-1}\right)=0.025$ & 0.74 \\
& Biochar $450^{\circ} \mathrm{C}$ & 0.22 & $k_{1}\left(1 . \mathrm{min}^{-1}\right)=0.051$ & 0.9 \\
& Biochar $600^{\circ} \mathrm{C}$ & 0.24 & $k_{1}(1 . \mathrm{min})=0.065$ & 0.89 \\
\hline \multirow{3}{*}{ Pseudo-second-order } & Biochar $300^{\circ} \mathrm{C}$ & 0.77 & $\left.k_{2}\left(\mathrm{~g} \cdot \mathrm{mg}^{-1} \cdot \mathrm{min}^{-1}\right)\right)=0.314$ & 0.69 \\
& Biochar $450^{\circ} \mathrm{C}$ & 0.78 & $\left.k_{2}\left(\mathrm{~g} \cdot \mathrm{mg}^{-1} \cdot \mathrm{min}^{-1}\right)\right)==0.200$ & 0.74 \\
& Biochar $600^{\circ} \mathrm{C}$ & 0.75 & $\left.k_{2}\left(\mathrm{~g} \cdot \mathrm{mg}^{-1} \cdot \mathrm{min}^{-1}\right)\right)==0.247$ & 0.70 \\
\hline
\end{tabular}

\section{Conclusions}

Coffee husks acquired from Krong Buk Town (Dak Lak Province, Vietnam) were used to transform into/produce biochar. Recovery efficiency and surface physical-chemical properties of the biochar (TOC, $\mathrm{pH}, \mathrm{pH}_{\mathrm{pzc}}, \mathrm{H}^{+}$and $\mathrm{OH}^{-}$ groups, and $\mathrm{CEC}$ ) at different temperatures were determined. The results showed that biochar pyrolysis temperatures were positively correlated with $\mathrm{pH}, \mathrm{pH}_{\mathrm{pzc}}$, and $\mathrm{mmolOH}^{-}$and negatively with $\% \mathrm{H}, \mathrm{mmolH}^{+}, \% \mathrm{TOC}$, and CEC. The study showed biochar derived from coffee husks with lower pyrolysis temperature had higher $\mathrm{NH}_{4}^{+}$adsorption capacity. Both Langmuir and Freundlich isotherm models fit the $\mathrm{NH}_{4}^{+}$adsorption process with $R^{2}$ in range 0.91-0.98. Time to reach adsorption equilibrium ranged from 15 to 30 minutes. The pseudo-second-order kinetic model was used to explain $\mathrm{NH}_{4}^{+}$adsorption kinetics of coffee husks to derive biochar. In conclusion, a new idea of researching on the application of biochar produced from coffee husks in water treatments by $\mathrm{NH}_{4}^{+}$adsorption is based.

\section{Data Availability}

The data used to support the findings of this study are available from the corresponding author upon request.

\section{Conflicts of Interest}

The authors declare no conflicts of interest.

\section{Acknowledgments}

This research was supported by the Industrial University of Ho Chi Minh City, Vietnam.

\section{References}

[1] R. Knowles, D. R. S. Lean, and Y. K. Chan, "Nitrous oxide concentrations in lakes: Variations with depth and time1," Limnology and Oceanography, vol. 26, no. 5, pp. 855-866, 1981.

[2] D. Hsu, C. Lu, T. Pang, Y. Wang, and G. Wang, "Adsorption of ammonium nitrogen from aqueous solution on chemically activated biochar prepared from sorghum distillers grain," Applied Sciences, vol. 9, no. 23, pp. 1-16, 2019.

[3] F. B. Eddy, "Ammonia in estuaries and effects on fish," Journal of Fish Biology, vol. 67, no. 6, pp. 1495-1513, 2005.

[4] WHO, Ammonia in Drinking-Water in Health Criteria and Other Supporting Information, World Health Organization, Geneva, Switzerland, 2nd edition, 1996.
[5] A. Khalil, N. Sergeevich, and V. Borisova, "Removal of ammonium from fish farms by biochar obtained from rice straw Isotherm and kinetic studies for ammonium adsorption," Adsorption Science \& Technology, vol. 36, no. 5-6, pp. 12941309, 2018.

[6] C. Zhi-Liang, Z. Jian-Qiang, H. Ling, Y. Zhi-Hui, L. Zhao-Jun, and L. Min-Chao, "Removal of $\mathrm{Cd}$ and $\mathrm{Pb}$ with biochar made from dairy manure at low temperature," Journal of Integrative Agriculture, vol. 18, no. 1, pp. 201-210, 2019.

[7] T. Sizmur, T. Fresno, G. Akgül, H. Frost, and E. MorenoJiménez, "Biochar modification to enhance sorption of inorganics from water," Bioresource Technology, vol. 246, pp. 34-47, 2017.

[8] X. Gai, H. Wang, J. Liu et al., "Effects of feedstock and pyrolysis temperature on biochar adsorption of ammonium and nitrate," PLoS One, vol. 9, no. 12, Article ID e113888, 2014.

[9] Z. Zhou, Z. Xu, Q. Feng, D. Yao, J. Yu, and D. Wang, "Effect of pyrolysis condition on the adsorption mechanism of lead, cadmium and copper on tobacco stem biochar," Journal of Cleaner Production, vol. 187, pp. 1-26, 2018.

[10] R. B. Fidel, D. A. Laird, and K. A. Spokas, "Sorption of ammonium and nitrate to biochars is electrostatic and $\mathrm{pH}$ dependent," Scientific Reports, vol. 8, Article ID 17627, 2018.

[11] United States Department of Agriculture: Coffee: World Markets and Trade https://downloads.usda.library.cornell. edu/usda-esmis/files/m900nt40f/sq87c919h/8w32rm91m/ coffee.pdf.

[12] M. Thong, https://daklak24h.com.vn/kinh-te/10306/su-dungvo-ca-phe-cho-san-xuat-cong-nghiep-hieu-qua-van-chuacao.html, 2015.

[13] V.-P. Dinh, T.-D.-T. Huynh, H. M. Le et al., "Insight into the adsorption mechanisms of methylene blue and chromium(iii) from aqueous solution onto pomelo fruit peel," RSC Advances, vol. 9, no. 44, pp. 25847-25860, 2019.

[14] N. Van Cuong, T. Q. Hieu, P. T. Thien, and T. L. V. LD Vu, "Reusable starch-graft-polyaniline/Fe3O4 composite for removal of textile dyes," Rasayan Journal of Chemistry, vol. 10, no. 4, pp. 1446-1454, 2017.

[15] P. T. Long, D. V. Dat, and L. V. Tan, "Modeling synthesis amorphous magnesium silicate for adsorption of lead, cadmium and arsenic on well-developed surface area in aqueous solution," Rasayan Journal Chemical, vol. 14, no. 1, pp. 608-615, 2021.

[16] Y. K. Kiran, A. Barkat, X.-q. Cui et al., "Cow manure and cow manure-derived biochar application as a soil amendment for reducing cadmium availability and accumulation by Brassica chinensis L. in acidic red soil," Journal of Integrative Agriculture, vol. 16, no. 3, pp. 725-734, 2017.

[17] CEN/T. S. 14429, Characterization of Waste - Leaching Behaviour Test - Influence of $\mathrm{pH}$ on Leaching with Initial Acid/ base Addition, European Committee For Standardization, Brussels, Belgium, 2005. 
[18] G. Yoo, H. Kim, J. Chen, and Y. Kim, "Effects of biochar addition on nitrogen leaching and soil structure following fertilizer application to rice paddy soil," Soil Science Society of America Journal, vol. 78, no. 3, pp. 852-860, 2014.

[19] T. T. Tu., "Physicaland chemical chareterization of biochar derived from rice husk," Journal of Hue University, vol. 120, no. 6, pp. 233-247, 2016.

[20] TCVN 8941, "Soil quality-determination of total organic carbon-walkey black method," Vietnam Standard, vol. 99, 2011.

[21] W. H. Cheung, S. S. Y. Lau, S. Y. Leung, A. W. M. Ip, and G. McKay, "Characteristics of chemical modified activated carbons from bamboo scaffolding," Chinese Journal of Chemical Engineering, vol. 20, no. 2, pp. 515-523, 2012.

[22] S. Xue, X. Zhang, H. H. Ngo et al., "Food waste based biochars for ammonia nitrogen removal from aqueous solutions," Bioresource Technology, vol. 292, Article ID 121927, 2019.

[23] S. Yavari, A. Malakahmad, and N. B. Sapari, "Effects of production conditions on yield and physicochemical properties of biochars produced from rice husk and oil palm empty fruit bunches," Environmental Science and Pollution Research International, vol. 23, no. 18, pp. 17928-17940, 2016.

[24] M.-E. Lee, J. H. Park, and J. W. Chungg, "Adsorption of $\mathrm{Pb}$ (II) and $\mathrm{Cu}(\mathrm{II})$ by ginkgo-leaf-derived biochar produced under various carbonization temperatures and times," International Journal of Environmental Research and Public Health, vol. 12, p. 14, 2017.

[25] X. Xu, X. Cao, L. Zhao, H. Wang, H. Yu, and B. Gao, "Removal of $\mathrm{Cu}, \mathrm{Zn}$, and $\mathrm{Cd}$ from aqueous solutions by the dairy manure-derived biochar," Environmental Science and Pollution Research, vol. 20, no. 1, pp. 358-368, 2013.

[26] A. Mukherjee, A. R. Zimmerman, and W. Harris, "Surface chemistry variations among a series of laboratory-produced biochars," Geoderma, vol. 163, no. 3-4, pp. 247-255, 2011.

[27] X. Yang, S. Zhang, M. Ju, and L. Liu, "Preparation and modification of biochar materials and their application in soil remediation," Applied Sciences, vol. 9, no. 7, pp. 2-25, 2019.

[28] N.-T. Vu and K.-U. Do, Insights into Adsorption of Ammonium by Biochar Derived from Low Temperature Pyrolysis of Coffee Husk, Biomass Conversion and Biorefinery, Springer, Berlin, Germany, 2021.

[29] Y. Ding, Y. Liu, S. liu, Z. Li, X. Tan, X. Huang et al., "Competitive removal of $\mathrm{Cd}$ (II) and $\mathrm{Pb}$ (II) by biochars produced from water hyacinths performance and mechanism," RSC Advances, vol. 6, pp. 1-28, 2016.

[30] Y. V. Lugovoy, K. V. Chalov, Y. Y. Kosivtsov, A. A. Stepacheva, and E. M. Sulman, "Effect of metal chlorides on the pyrolysis of wheat straw," International Journal of Chemical Engineering, vol. 2019, Article ID 7135235, 10 pages, 2019.

[31] M. H. Park, S. Jeong, and J. Y. Kim, "Peer Review \#1 of Longterm effects of straw and straw-derived biochar on soil aggregation and fungal community in a rice-wheat rotation system (v0.1)," Journal of Environmental Chemical Engineering, vol. 7, pp. 1-7, 2019.

[32] S. A. Begum, A. H. M. G. Hyder, Q. Hicklen, T. Crocker, and B. Oni, "Adsorption characteristics of ammonium onto biochar from an aqueous solution," Journal of Water Supply Research and Technology-Aqua, vol. 70, no. 1, pp. 1-10, 2021.

[33] F. Gao, Y. Xue, X. Cheng, K. Yang, and K. Yanga, "Removal of aqueous ammonium by biochars derived from agricultural residuals at different pyrolysis temperatures," Chemical Speciation \& Bioavailability, vol. 27, no. 2, pp. 92-97, 2015.
[34] R. Fan, C.-l. Chen, J.-y. Lin et al., "Adsorption characteristics of ammonium ion onto hydrous biochars in dilute aqueous solutions," Bioresource Technology, vol. 272, pp. 465-472, 2019.

[35] B. Wang, J. Lehmann, K. Hanley, R. Hestrin, and A. Enders, "Adsorption and desorption of ammonium by maple wood biochar as a function of oxidation and $\mathrm{pH}$," Chemosphere, vol. 138, pp. 120-126, 2015.

[36] S. X. Zhao, N. Ta, and X. D. Wang, "Effect of temperature on the structural and physicochemical properties of biochar with apple tree branches as feedstock material," Energies, vol. 10, no. 9, 2017.

[37] Y. S. Ho and G. McKay, "Pseudo-second order model for sorption processes," Process Biochemistry, vol. 34, no. 5, pp. 451-465, 1999. 